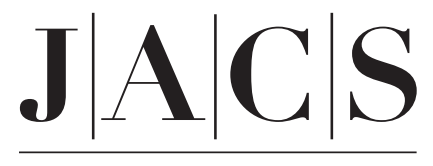

A R T I C L E S

Published on Web 11/04/2005

\title{
Hydrogen Storage in Magnesium Clusters: Quantum Chemical Study
}

\author{
Rudy W. P. Wagemans, ${ }^{\dagger}$ Joop H. van Lenthe, ${ }^{\ddagger}$ Petra E. de Jongh, ${ }^{\dagger}$ \\ A. Jos van Dillen, ${ }^{\dagger}$ and Krijn P. de Jong*, ${ }^{*}$ \\ Contribution from the Department of Inorganic Chemistry and Catalysis and the Theoretical \\ Chemistry Group, Debye Institute, Utrecht University, P. O. Box 80083, \\ NL-3508TC Utrecht, The Netherlands
}

Received July 10, 2005; E-mail: k.p.dejong@chem.uu.nl

\begin{abstract}
Magnesium hydride is cheap and contains $7.7 \mathrm{wt} \%$ hydrogen, making it one of the most attractive hydrogen storage materials. However, thermodynamics dictate that hydrogen desorption from bulk magnesium hydride only takes place at or above $300{ }^{\circ} \mathrm{C}$, which is a major impediment for practical application. A few results in the literature, related to disordered materials and very thin layers, indicate that lower desorption temperatures are possible. We systematically investigated the effect of crystal grain size on the thermodynamic stability of magnesium and magnesium hydride, using ab initio Hartree-Fock and density functional theory calculations. Also, the stepwise desorption of hydrogen was followed in detail. As expected, both magnesium and magnesium hydride become less stable with decreasing cluster size, notably for clusters smaller than 20 magnesium atoms. However, magnesium hydride destabilizes more strongly than magnesium. As a result, the hydrogen desorption energy decreases significantly when the crystal grain size becomes smaller than $\sim 1.3 \mathrm{~nm}$. For instance, an $\mathrm{MgH}_{2}$ crystallite size of $0.9 \mathrm{~nm}$ corresponds to a desorption temperature of only $200^{\circ} \mathrm{C}$. This predicted decrease of the hydrogen desorption temperature is an important step toward the application of $\mathrm{Mg}$ as a hydrogen storage material.
\end{abstract}

\section{Introduction}

Hydrogen is an ideal clean carrier for storage, transport, and conversion of energy. However, a key problem is its storage, especially for its use as a fuel for zero-emission mobile applications. Physical storage of hydrogen, as a highly pressurized gas or in a liquid phase at low temperatures, is associated with significant security risks, energy losses, and high volumes. ${ }^{1,2}$ Furthermore, physical adsorption of hydrogen onto lightweight nanomaterials, such as zeolites, carbon nanotubes, and activated carbons, yields only low storage densities and also needs low temperatures. ${ }^{3-8}$ The alternative is chemical storage: the reversible absorption of hydrogen into another material. Especially metal hydrides offer a promising and safe alternative to storage in compressed or liquid form. ${ }^{9,10}$

\footnotetext{
Department of Inorganic Chemistry and Catalysis.

$\div$ Theoretical Chemistry Group.

(1) Schlapbach, L.; Zuttel, A. Nature 2001, 414 (6861), 353-358.

(2) Zuttel, A. Naturwissenschaften 2004, 91 (4), 157-172.

(3) Zecchina, A.; Bordiga, S.; Vitillo, J. G.; Ricchiardi, G.; Lamberti, C.; Spoto, G.; Bjorgen, M.; Lillerud, K. P. J. Am. Chem. Soc. 2005, 127 (17), $6361-$ 6366.

(4) Hirscher, M.; Becher, M.; Haluska, M.; Dettlaff-Weglikowska, U.; Quintel, A.; Duesberg, G. S.; Choi, Y. M.; Downes, P.; Hulman, M.; Roth, S.; Stepanek, I.; Bernier, P. Appl. Phys. A: Mater. Sci. Process. 2001, 72 (2), 129-132.

(5) Terres, E.; Panella, B.; Hayashi, T.; Kim, Y. A.; Endo, M.; Dominguez, J. M.; Hirscher, M.; Terrones, H.; Terrones, M. Chem. Phys. Lett. 2005, 403 $(4-6), 363-366$.

(6) Dillon, A. C.; Heben, M. J. Appl. Phys. A: Mater. Sci. Process. 2001, 72 (2), $133-142$

(7) Nijkamp, M. G.; Raaymakers, J.; van Dillen, A. J.; de Jong, K. P. Appl. Phys. A: Mater. Sci. Process. 2001, 72 (5), 619-623.

(8) Schimmel, H. G.; Kearley, G. J.; Nijkamp, M. G.; Visserl, C. T.; de Jong, K. P.; Mulder, F. M. Chem.-Eur. J. 2003, 9 (19), 4764-4770.
}

10.1021/ja054569h CCC: $\$ 30.25 \odot 2005$ American Chemical Society
Hydrogen storage in metal hydrides has been the focus of intensive research. Magnesium dihydride combines a high $\mathrm{H}_{2}$ capacity of 7.7 wt \% with the benefit of the low cost of the abundantly available magnesium. ${ }^{11-13}$ The main barriers for direct usage of pure $\mathrm{MgH}_{2}$ are slow desorption kinetics, a high thermodynamic stability, and a high reactivity toward air and oxygen which it has in common with most other lightweight metal hydrides. ${ }^{14,15}$ The high thermodynamic stability of $\mathrm{MgH}_{2}$ results in a relatively high desorption enthalpy, which corresponds to an unfavorable desorption temperature of $573 \mathrm{~K}$ at 1 bar $\mathrm{H}_{2} \cdot{ }^{9,11,16}$ During the past two decades research efforts were devoted to modifying the $\mathrm{Mg}$-based system, aiming at increasing the absorption/desorption rates and lowering the desorption temperature. Different approaches were reported, mainly involving alloying $\mathrm{Mg}$ with other elements, high energy or reactive ball milling of $\mathrm{Mg}$, or surface modification of $\mathrm{Mg} .{ }^{17-25}$ Many

(9) Huot, J.; Liang, G.; Schulz, R. Appl. Phys. A: Mater. Sci. Process. 2001, 72 (2), 187-195.

(10) Zaluska, A.; Zaluski, L.; Strom-Olsen, J. O. Appl. Phys. A: Mater. Sci. Process. 2001, 72 (2), 157-165.

(11) Imamura, H.; Masanari, K.; Kusuhara, M.; Katsumoto, H.; Sumi, T.; Sakata, Y. J. Alloys Compd. 2005, 386 (1-2), 211-216.

(12) Zaluski, L.; Zaluska, A.; Strom-Olsen, J. O. J. Alloys Compd. 1997, 253, 70-79.

(13) Liang, G.; Huot, J.; Boily, S.; Van Neste, A.; Schulz, R. J. Alloys Compd. 1999, $291(1-2), 295-299$.

(14) Zaluska, A.; Zaluski, L.; Strom-Olsen, J. O. J. Alloys Compd. 1999, 288 $(1-2), 217-225$.

(15) Barkhordarian, G.; Klassen, T.; Bormann, R. J. Alloys Compd. 2004, 364 $(1-2), 242-246$

(16) Grochala, W.; Edwards, P. P. Chem. Rev. 2004, 104 (3), 1283-1315.

(17) Vegge, T.; Hedegaard-Jensen, L. S.; Bonde, J.; Munter, T. R.; Norskov, J. K. J. Alloys Compd. 2005, $386(1-2), 1-7$. 
of these techniques are suitable to improve the kinetics drastically, increasing sorption rates by up to 2 orders of magnitude. This can be ascribed mainly to surface enlargement, dissolution of other metals into $\mathrm{Mg}$ (disruption of the $\mathrm{Mg}$ crystalline structure), decreasing diffusion lengths, and breaking up the inhibiting and passivating outer oxide layer. However, upscaling of milling is not straightforward and this technique is limited to grain sizes down to $10-50 \mathrm{~nm}$ for pure $\mathrm{Mg}$. More importantly, the thermodynamics are not affected by such techniques, so the desorption temperature of $\mathrm{MgH}_{2}$ cannot be lowered below that of the bulk value of $573 \mathrm{~K}$. Although some alloying or doping techniques are able to affect the desorption temperature, this is accompanied by a lower hydrogen storage capacity due to the added weight. ${ }^{10,26-28}$ Furthermore, the positive effects on sorption temperatures and rates of these milled and/or doped $\mathrm{Mg}$ compounds are often lost in the first few cycles of charging and discharging with hydrogen. A similar effect is observed with other bulk phases of magnesium hydride. ${ }^{9,13,29-33} \gamma-\mathrm{MgH}_{2}$ is a less stable phase than the more common $\beta-\mathrm{MgH}_{2}$, but the improvement in desorption temperature is lost after the first hydrogenation/dehydrogenation cycle, upon which $\beta-\mathrm{MgH}_{2}$ is formed. Lower desorption temperatures have also been reported for sputtered thin films of $\mathrm{Mg}$, mostly capped with a Pd layer, or for highly amorphous Mg. ${ }^{26,34}$ For these materials the desorption temperatures are more stable upon cycling, but this effect is not yet understood, although it might be related to the presence of the Pd.

These promising results have stimulated us to consider in more detail the thermodynamic stability of $\mathrm{MgH}_{2}$ versus $\mathrm{Mg}+$ $\mathrm{H}_{2}$ as a function of crystal grain size. The classical Born-Haber cycle for the magnesium-hydrogen system is shown in Figure 1. Although $\mathrm{MgH}_{2}$ is not an entirely ionic structure as assumed in this thermodynamic cycle, the general scheme can be used as a first approximation. ${ }^{35-37}$ The lattice energy for $\mathrm{MgH}_{2}$ is considerably larger than that for $\mathrm{Mg}$ and is also ca. 36 times

(18) Au, M. Mater. Sci. Eng., B: Solid State Mater. Adv. Technol. 2005, 117 (1), 37-44.

(19) Liang, G. J. Alloys Compd. 2004, 370 (1-2), 123-128.

(20) Oelerich, W.; Klassen, T.; Bormann, R. Mater. Trans. 2001, 42 (8), 15881592.

(21) Huot, J.; Liang, G.; Schulz, R. J. Alloys Compd. 2003, 353 (1-2), L12L15.

(22) Oelerich, W.; Klassen, T.; Bormann, R. J. Alloys Compd. 2001, 315 $(1-2), 237-242$

(23) Huot, J.; Swainson, I. P.; Schulz, R. J. Alloys Compd. 1999, 292 (1-2), $292-295$.

(24) Wang, X. L.; Suda, S. J. Alloys Compd. 1995, 231 (1-2), 380-386.

(25) Liang, G.; Huot, J.; Boily, S.; Schulz, R. J. Alloys Compd. 2000, 305 $(1-2), 239-245$.

(26) Higuchi, K.; Kajioka, H.; Toiyama, K.; Fujii, H.; Orimo, S.; Kikuchi, Y. J. Alloys Compd. 1999, 295, 484-489.

(27) Chen, J.; Yang, H. B.; Xia, Y. Y.; Kuriyama, N.; Xu, Q.; Sakai, T. Chem. Mater. 2002, 14 (7), 2834-2836.

(28) Orimo, S.; Fujii, H. Appl. Phys. A: Mater. Sci. Process. 2001, 72 (2), 167186.

(29) Schimmel, H. G. Thesis, Delft University of Technology, 2004.

(30) Vajeeston, P.; Ravindran, P.; Kjekshus, A.; Fjellvag, H. Phys. Rev. Lett. 2002, 89 (17), 1755061-1755064.

(31) Yavari, A. R.; de Castro, J. F. R.; Vaughan, G.; Heunen, G. J. Alloys Compd. 2003, 353 (1-2), 246-251.

(32) Schimmel, H. G.; Johnson, M. R.; Kearley, G. J.; Ramirez-Cuesta, A. J.; Huot, J.; Mulder, F. M. Mater. Sci. Eng., B: Solid State Mater. Adv. Technol. 2004, $108(1-2), 38-41$

(33) Wang, P.; Zhang, H. F.; Ding, B. Z.; Hu, Z. Q. J. Alloys Compd. 2000, $313,209-213$.

(34) Higuchi, K.; Yamamoto, K.; Kajioka, H.; Toiyama, K.; Honda, M.; Orimo, S.; Fujii, H. J. Alloys Compd. 2002, 330, 526-530.

(35) Ohba, N.; Miwa, K.; Noritake, T.; Fukumoto, A. Phys. Rev. B 2004, 70 (3), 0351021-0351027

(36) Noritake, T.; Towata, S.; Aoki, M.; Seno, Y.; Hirose, Y.; Nishibori, E.; Takata, M.; Sakata, M. J. Alloys Compd. 2003, 356, 84-86.

(37) Noritake, T.; Aoki, M.; Towata, S.; Seno, Y.; Hirose, Y.; Nishibori, E.; Takata, M.; Sakata, M. Appl. Phys. Lett. 2002, 81 (11), 2008-2010.

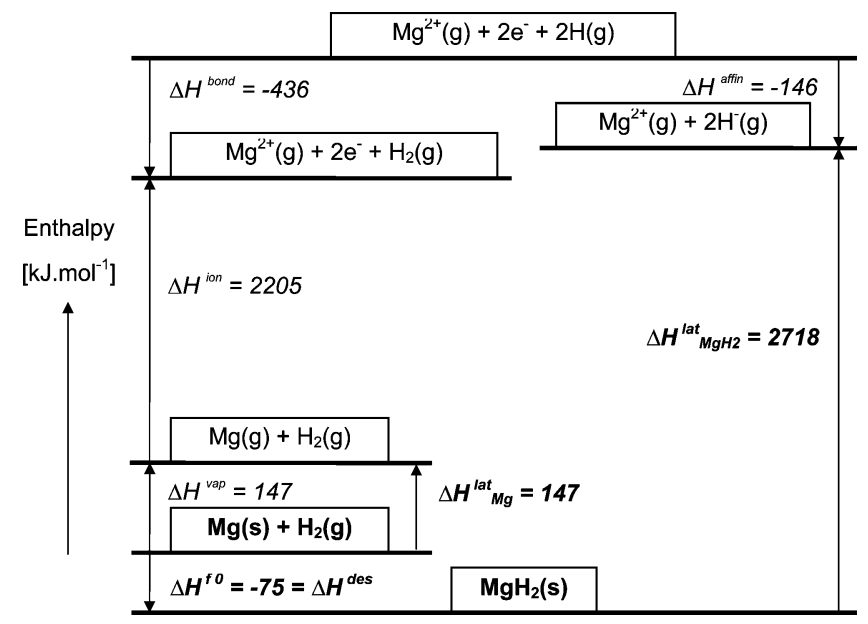

Figure 1. Born-Haber cycle for the bulk $\mathrm{Mg}-\mathrm{H}_{2}$ system at standard pressure and temperature $\left(1 \times 10^{5} \mathrm{~Pa}, 298 \mathrm{~K}\right)$. The lattice enthalpies $\left[\mathrm{kJ} \cdot \mathrm{mol}^{-1}\right]$ are given in bold, as is the formation enthalpy of $\mathrm{MgH}_{2}$, which corresponds to the desorption enthalpy.

larger than the desorption enthalpy. Therefore, a relatively small shift in the lattice enthalpies can have a large impact on the desorption enthalpy. In general, the specific lattice enthalpy decreases upon lowering the amount of atoms in a cluster $\left(\mathrm{Mg}_{x}\right.$ or $\operatorname{Mg}_{x} \mathrm{H}_{2 x}$ ), due to the decreased average coordination number of the atoms. Distortions of the $\mathrm{Mg}\left(\mathrm{H}_{2}\right)$ lattice can be expected to result in a shift in the lattice enthalpy, similar to what is seen for alloyed magnesium. ${ }^{17,38-41}$

For main group metals, the electronic structure varies with the number of interacting atoms. ${ }^{42-45}$ The equilibrium geometries and electronic structures of small magnesium clusters have been described in the literature for different quantum chemical methods. ${ }^{46-54}$ For thin magnesium layers a decrease in potential energy was reported upon decreasing the layer thickness in one dimension. ${ }^{39}$ Although quantum chemical calculations have been performed for other metal hydrides and molecules, a systematic study on the geometry and stability of $\mathrm{MgH}_{2}$ as a function of cluster size has not yet been reported. ${ }^{55}$ In this paper we present

(38) Liang, J. J.; Khosrovani, N. Prepr. Pap.-Am. Chem. Soc., Div. Fuel Chem. 2004, 49 (1), 152-154.

(39) Liang, J. J. Appl. Phys. A: Mater. Sci. Process. 2005, 80 (1), 173-178

(40) Bach, F. W.; Schaper, M.; Jaschik, C. Influence of lithium on hcp magnesium alloys. In Magnesium Alloys 2003, Parts 1 And 2 Materials Science Forum 419-4; Trans Tech Publications Ltd.: Zurich, Switzerland, 2003; pp 1037-1042.

(41) Notten, P. H. L.; Outwerkerk, M.; van Hal, H.; Beelen, D.; Keur, W.; Zhou, J.; Feil, H. J. Power Sources 2004, 129 (1), 45-54.

(42) Bandow, S.; Kumura, K. Solid State Commun. 1990, 73 (2), 167-171.

(43) Sichel, E. K.; Gittleman, J. I.; Abeles, B. Thin Solid Films 1978, 51, 8992.

(44) Millet, J.-L.; Borel, J.-P. Solid State Commun. 1982, 43 (3), 217-220.

(45) Belanzoni, P.; van Lenthe, E.; Baerends, E. J. J. Chem. Phys. 2001, 114 (10), 4421-4433.

(46) Diederich, T.; Doppner, T.; Braune, J.; Tiggesbaumker, J.; Meiwes-Broer K. H. Phys. Rev. Lett. 2001, 86 (21), 4807-4810.

(47) Tsuda, M.; Dino, W. A.; Nakanishi, H.; Kasai, H. J. Phys. Soc. Jpn. 2004 73 (10), 2628-2630.

(48) Lyalin, A.; Solovyov, I. A.; Solovyov, A. V.; Greiner, W. Phys. Rev. A 2003, 67 (6), 851-859.

(49) Thomas, O. C.; Zheng, W. J.; Xu, S. J.; Bowen, K. H. Phys. Rev. Lett. 2002, 89 (21), 213403-1.

(50) Davidson, E. R.; Frey, R. F. J. Chem. Phys. 1997, 106 (6), 2331-2341.

(51) Wang, Y. J.; Yuan, H. T.; Wang, L. B.; Cao, J. S.; Li, Q. D. Rare Met. Mater. Eng. 2001, 30, 267-270.

(52) Griessen, R.; Driessen, A. Phys. Rev. B 1984, 30 (8), 4372-4382.

(53) Bogdanovic, B.; Bohmhammel, K.; Christ, B.; Reiser, A.; Schlichte, K.; Vehlen, R.; Wolf, U. J. Alloys Compd. 1999, 282 (1-2), 84-92.

(54) Bohmhammel, K.; Wolf, U.; Wolf, G.; Konigsberger, E. Thermochim. Acta 1999, $337(1-2), 195-199$.

(55) Smithson, H.; Marianetti, C. A.; Morgan, D.; Van der Ven, A.; Predith, A.; Ceder, G. Phys. Rev. B 2002, 66 (14), 144107. 


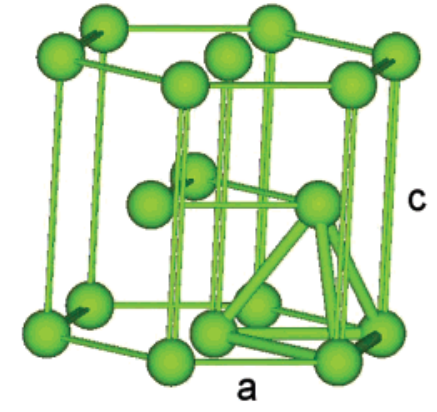

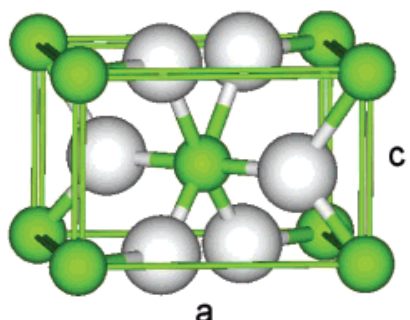

b) $\mathrm{MgH}_{2}$ crystal

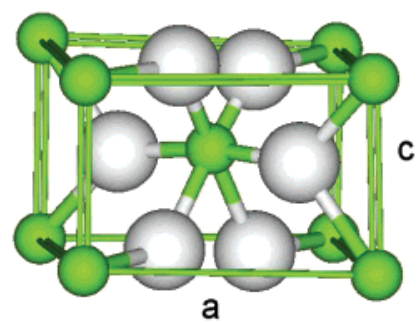

c) $\mathrm{Mg}_{30} \mathrm{H}_{60}$ DFT(B97)

\begin{abstract}
a) Mg crystal
a theoretical investigation of the cluster size dependency of the (de)sorption enthalpy by calculations on $\mathrm{Mg}$ and $\mathrm{MgH}_{2}$ clusters. $\mathrm{Ab}$ initio calculations have been applied for clusters with up to 30 magnesium atoms. For larger clusters up to 56 magnesium atoms, pseudopotentials and density functional theory methods were used. When the potential energies for both $\mathrm{Mg}$ and $\mathrm{MgH}_{2}$ clusters are calculated in a consistent manner, a direct relation between cluster size and the energy can be made. By comparing the stabilities of small metallic and hydride clusters, we can predict changes in (equilibrium) thermodynamics, which can have a large impact on the desorption temperature.
\end{abstract}

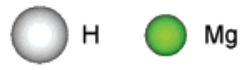

Figure 2. Structures of (a) unit cell of bulk Mg, (b) unit cell of bulk $\beta-\mathrm{MgH}_{2}$, and (c) core of $\mathrm{Mg}_{30} \mathrm{H}_{60}$.

\section{Methods}

To evaluate the desorption enthalpy, the energies of both $\mathrm{Mg}$ and $\mathrm{MgH}_{2}$ clusters are needed. For all clusters considered, the geometry with the lowest possible energy was determined in a gradient-driven geometry optimization, after which the zero point vibrational energy (ZPE) was calculated for that geometry using analytical Hessians. ${ }^{56}$ Reaction 1 represents the desorption of hydrogen from a magnesium hydride cluster:

$$
\operatorname{Mg}_{x} \mathrm{H}_{2 x}(\mathrm{~s}) \rightarrow \mathrm{Mg}_{x}(\mathrm{~s})+x \mathrm{H}_{2}(\mathrm{~g})
$$

The energies $\left(E_{\min }\right.$ and $\left.\mathrm{ZPE}\right)$ of all components involved in this reaction were calculated for a range of cluster sizes up to $56 \mathrm{Mg}$ atoms. Where possible, the values for $\mathrm{Mg}$ were compared with those from the literature. Contrary to the solid clusters, the hydrogen molecules are in the gas phase. Since the hydrogen molecules are relatively far apart, their intermolecular interactions are negligible. The desorption enthalpy can be approximated by the desorption energy $\left(\Delta H^{\mathrm{des}} \cong \Delta E^{\mathrm{des}}\right)$, because both the contributing $\Delta\left[\begin{array}{ll}p & \mathrm{~d} V\end{array}\right]$ and $\Delta\left[c_{p} \mathrm{~d} T\right]$ terms are small in comparison to the energy term over the whole reaction. The energy of the reaction was taken as the difference in calculated energies, as shown in eq 2 .

$$
\Delta E^{\text {des }} \cong E\left[\mathrm{Mg}_{x}\right]+x E\left[\mathrm{H}_{2}\right]-E\left[\mathrm{Mg}_{x} \mathrm{H}_{2 x}\right]
$$

With the ab initio restricted Hartree-Fock (HF) method, the desired energies can be calculated for clusters up to $30 \mathrm{Mg}$ atoms. The used basis set was SV 6-31G, ${ }^{57}$ and the geometries were optimized with a convergence threshold of $0.001 E_{\mathrm{h}} \cdot a_{0}^{-1}$ in the gradient.

To validate the calculation method, we verified whether the calculated desorption energies were in good agreement with the bulk experimental value of $75 \mathrm{~kJ} \cdot \mathrm{mol}\left[\mathrm{H}_{2}\right]^{-1}$ for large cluster sizes. With the use of a pseudopotential for $\mathrm{Mg}$, the energies for clusters up to 56 $\mathrm{Mg}$ atoms could be calculated. For these calculations we incorporated density functional theory (DFT) to obtain a comparison with results taken from calculations on magnesium metal clusters and the bulk values for the desorption enthalpies. For the DFT calculations, the B97 functional ${ }^{58}$ was used with the ECP basis set with a double- $\zeta$ contraction (ECPDZ) for magnesium, and a convergence threshold of $0.002 E_{\mathrm{h}}{ }^{*} a_{0}^{-1}$ in the gradient. The B97 functional has been shown in the past to yield reasonable results for small molecules or clusters, both with and without metal atoms. All calculations were performed with the GAMESS-UK program, version 6.0 , on the TERAS computer of SARA. ${ }^{59}$

\section{Results and Discussion}

3.1. Geometric Optimization and Validation. To validate the geometric optimization for both calculation methods, all structures were checked for plausibility, meaning no emerging hydrogen molecules and a narrow distribution for the $\mathrm{Mg}-\mathrm{Mg}$, $\mathrm{H}-\mathrm{H}$, and $\mathrm{Mg}-\mathrm{H}$ bond lengths. Furthermore, different starting geometries were used for each cluster. The calculated geometries and energies for the $\mathrm{Mg}$ clusters were similar to those stated in the literature. ${ }^{39,48,50,60}$ The transition from the magnesium metal toward the magnesium hydride is accompanied by a large change in structure for the $\mathrm{Mg}$ atoms, as illustrated in Figure 2. Upon charging with hydrogen, the metallic $\mathrm{Mg}$ atoms trade their hexagonal environment of the hep structure for a bcc sublattice in the rutile structure. The atomic radius of magnesium shrinks upon becoming partly cationic. This yields enough space for the large hydrogen atoms (anions) to be inserted, creating the rutile-like $\left(\mathrm{TiO}_{2}\right) \mathrm{MgH}_{2}$ structure, with a molar volume increase of $30 \%$. Figure 2 also shows a representative example of the most stable calculated structure for the core of the larger systems.

Table 1 lists the cell parameters and atomic distances, both reference values, and the values calculated for the $\mathrm{Mg}_{30} \mathrm{H}_{60}$ cluster. The average values for the core of the cluster are close to the reference values for $\beta-\mathrm{MgH}_{2}$ obtained from crystallographic data. In general, when the $\mathrm{MgH}_{2}$ clusters contain more than $19 \mathrm{Mg}$ atoms, the inner nine $\mathrm{Mg}$ atoms form a rutile-type

(56) Frankcombe, T. J.; Kroes, G. J.; Zuttel, A. Chem. Phys. Lett. 2005, 405 $(1-3), 73-78$

(57) Frish, M. J.; Pople, J. A.; Binkley, J. S. J. Chem. Phys. 1984, 80 (7), 32563269

(58) Becke, A. D. J. Chem. Phys. 1997, 107 (20), 8554-8560.

(59) Guest, M. F.; Lenthe, J. H. v.; Kendrick, J.; Schoeffel, K.; Sherwood, P. GAMESS-UK, A Package of Ab-Initio Programs, version 6.0; Computing for Science Ltd.: Daresbury, UK, 2004.

(60) Cheung, S.; Deng, W. Q.; van Duin, A. C. T.; Goddard, W. A. J. Phys. Chem. A 2005, 109 (5), 851-859. 
Table 1. Cell Parameters and Atomic Distances for Bulk Mg, Bulk $\mathrm{MgH}_{2}$, and Calculated Average Values for the Core of the $\mathrm{Mg}_{30} \mathrm{H}_{60}$ Cluster ${ }^{36,37}$

\begin{tabular}{llll}
\hline \multicolumn{1}{c}{ cell parameters } & \multicolumn{1}{c}{ crystal $\mathrm{Mg}$} & \multicolumn{1}{c}{ crystal $\beta-\mathrm{MgH}_{2}$} & $\mathrm{DFT}(\mathrm{B} 97) \mathrm{Mg}_{30} \mathrm{H}_{60}$ \\
\hline group & hcp, $p 63 / \mathrm{mmc}$ & rutile, $p 4 / m n m$ & \\
$a[\AA]$ & 3.21 & 4.52 & 4.54 \\
$c[\AA]$ & 5.21 & 3.02 & 2.96 \\
volume per $\mathrm{Mg}\left(\mathrm{H}_{2}\right)\left[\AA^{3}\right]$ & 23.2 & 30.8 & 30.5 \\
first shell $\mathrm{Mg}-\mathrm{H}[\AA]$ & & 1.96 & 1.97 \\
first shell $\mathrm{Mg}-\mathrm{Mg}[\AA] \mathrm{\AA}]$ & 3.20 & $3.02,3.54$ & $2.96,3.53$ \\
first shell $\mathrm{H}-\mathrm{H}[\AA]$ & & $2.76,3.02$ & $2.74,3.01$ \\
& & & \\
\hline
\end{tabular}

$\left(\mathrm{TiO}_{2}\right)$ structure, similar to that known for the bulk system. This result did not depend on the input geometry and was also found when starting with, for example, an hcp structure for $\mathrm{Mg}$ (bulk magnesium) with the hydrogen atoms placed randomly in the structure. Therefore, $\mathrm{MgH}_{2}$ clusters with more than $19 \mathrm{Mg}$ atoms can be expected to have electronic and energetic behavior similar to that of the bulk system. For Mg clusters, similar trends were reported for electronic properties, in which magnesium becomes metallic at 20 or $18 \mathrm{Mg}$ atoms. ${ }^{46,49}$

3.2. Energies of $\mathrm{Mg}$ and $\mathrm{MgH}_{2}$ as a Function of Cluster Size. With the DFT (B97) calculations, the energies were calculated for $\mathrm{Mg}$ and $\mathrm{MgH}_{2}$ clusters of up to $56 \mathrm{Mg}$ atoms. These values can be found in the electronic supporting material (Supporting Information). The absolute energies were first scaled with $\mathrm{Mg}$ or $\mathrm{MgH}_{2}$ as a reference energy, and subsequently divided by the number of $\mathrm{Mg}$ atoms in the cluster. A normalized energy per $\operatorname{Mg}\left(\mathrm{H}_{2}\right)$ unit was thus obtained, and with this procedure the cluster energies can be conveniently compared. Figure 3 shows the calculated energies for $\mathrm{Mg}$ and $\mathrm{MgH}_{2}$ as a function of cluster size.

Figure 3 shows that for both the $\mathrm{Mg}$ and $\mathrm{MgH}_{2}$ clusters the DFT calculated energies depend on the number of atoms in the cluster and therefore on the cluster size. When going down in cluster size, the relative energy of the clusters becomes less negative, which indicates a destabilization of small particles. This is what can be expected from first principles of physical properties. The surface-to-volume ratio increases upon decreas-

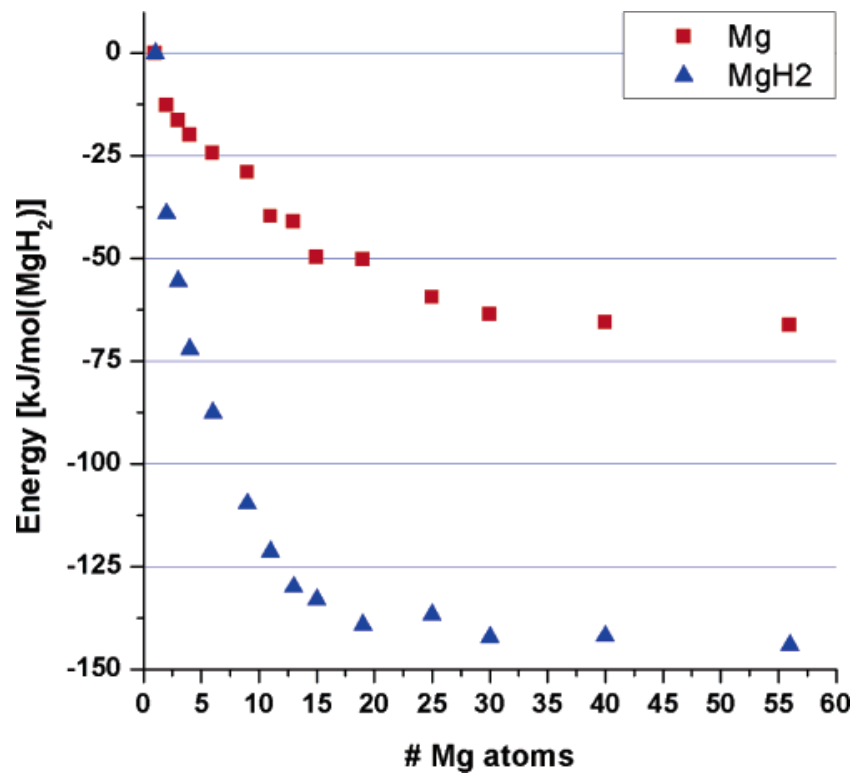

Figure 3. Energies for $\mathrm{Mg}$ and $\mathrm{MgH}_{2}$ clusters as a function of cluster size, calculated with the DFT method (B97 functional). The energies are scaled to the $\mathrm{Mg}$ or $\mathrm{MgH}_{2}$ cluster and normalized per $\mathrm{Mg}$ atom.

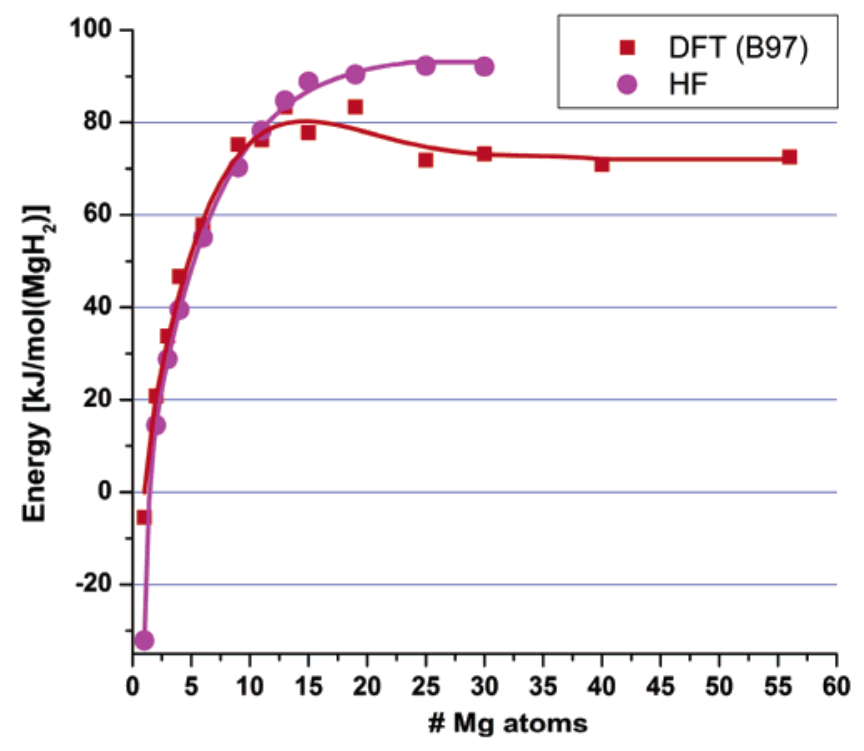

Figure 4. Calculated desorption energies for $\mathrm{MgH}_{2}$ clusters with both the HF method and DFT method (B97 functional). The energies are normalized per mole of $\mathrm{H}_{2}$ released.

ing the cluster size. Since the surface atoms have a lower coordination, the average number of bonds is lower for smaller clusters. For the metallic clusters a similar trend in desorption energy vs cluster size is found with the DFT method. However, the $\mathrm{MgH}_{2}$ clusters are more strongly destabilized than the corresponding $\mathrm{Mg}$ clusters upon decreasing the cluster size below $19 \mathrm{Mg}$ atoms.

3.3. Desorption Energies. With the cluster energies known, the desorption energies for $\mathrm{MgH}_{2}$ clusters can be calculated according to eq 2 . Figure 4 shows the results for both DFT and HF calculations.

The desorption energies converge to a constant value for clusters with more than $25 \mathrm{Mg}$ atoms: 92.3 and $72.5 \mathrm{~kJ} \cdot \mathrm{mol}$ $\left[\mathrm{H}_{2}\right]^{-1}$ for the $\mathrm{HF}$ and DFT methods, respectively. The convergence for the DFT method for clusters with more than 19 magnesium atoms is very close to the desorption enthalpy of $75 \mathrm{~kJ} \cdot \mathrm{mol}\left[\mathrm{H}_{2}\right]^{-1}$ for bulk $\beta-\mathrm{MgH}_{2}$. This, and the observation that for $\mathrm{MgH}_{2}$ clusters larger than $19 \mathrm{Mg}$ atoms the core of the clusters obtains a geometry similar to that of the bulk structure, shows the validity of the DFT calculations. The deviation from the bulk value of $17 \mathrm{~kJ} \cdot \mathrm{mol}\left[\mathrm{H}_{2}\right]^{-1}$ for the $\mathrm{HF}$ method can be ascribed to the fact that this method does not take the correlation energy into account.

Both methods give a similar trend: the desorption energy decreases as the cluster size is reduced below $19 \mathrm{Mg}$ atoms. This indicates that $\mathrm{MgH}_{2}$ clusters with a diameter below 1.3 $\mathrm{nm}$ can have a desorption behavior very different from that of bulk $\beta-\mathrm{MgH}_{2}$, enabling lower desorption temperatures. Upon downsizing the cluster toward the smallest stable cluster, $\mathrm{Mg}_{2} \mathrm{H}_{4}$, the desorption energy drops more than $70 \mathrm{~kJ} \cdot \mathrm{mol}\left[\mathrm{H}_{2}\right]^{-1}$. For instance, a desorption temperature of $473 \mathrm{~K}$ would be reached with a desorption enthalpy of $63 \mathrm{~kJ} \cdot \mathrm{mol}\left[\mathrm{H}_{2}\right]^{-1}$, corresponding to a $\mathrm{Mg}_{9} \mathrm{H}_{18}$ cluster size of $0.9 \mathrm{~nm}$. For the smallest possible cluster, $\mathrm{MgH}_{2}$, the desorption energy drops even to negative values, which means that the magnesium hydride molecule is not stable.

3.4. Stepwise Desorption. For clusters with 6 and $15 \mathrm{Mg}$ atoms, we followed the desorption process in more detail. 


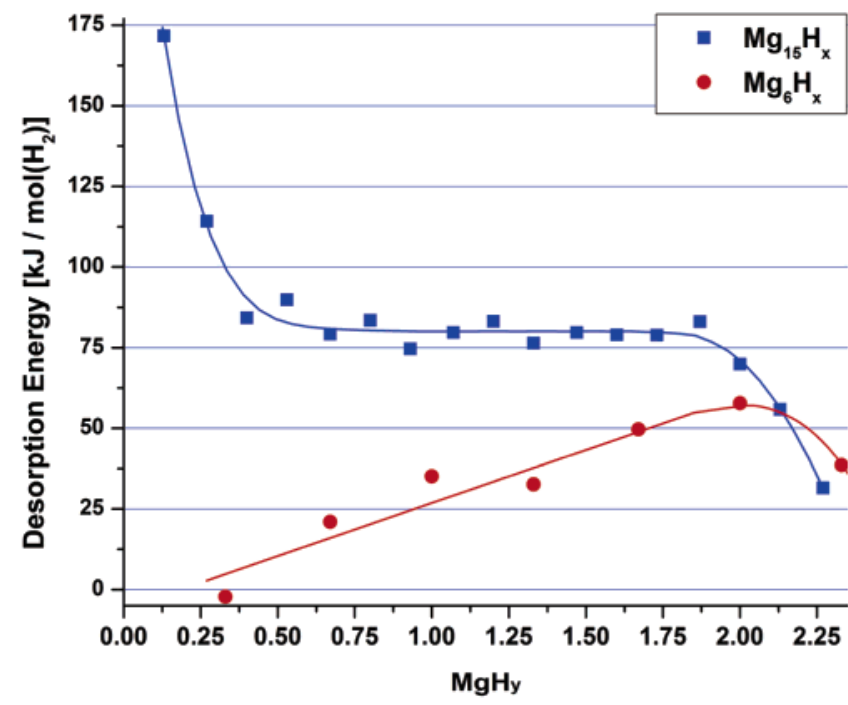

Figure 5. Energies of species involved in stepwise dehydrogenation of clusters with 6 and $15 \mathrm{Mg}$ atoms, calculated with DFT (B97). The relative desorption energies are normalized per mole of $\mathrm{H}_{2}$ released and plotted vs the $\mathrm{H} / \mathrm{Mg}$ ratio. The energies for the intermediate cluster $\mathrm{Mg}_{9} \mathrm{H}_{x}$ are presented in the Supporting Information.

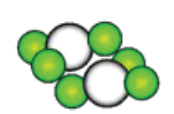

$\mathrm{Mg} 6 \mathrm{H}_{2}$

$\mathrm{MgH} 0.33$

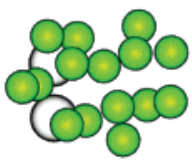

$\mathrm{Mg} 15 \mathrm{H}_{2}$

$\mathrm{MgH} 0.13$

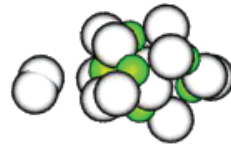

$\mathrm{Mg} 6 \mathrm{H}_{14}$

$\mathrm{MgH}_{2.33}$

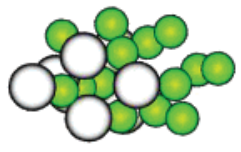

$\mathrm{Mg} 15 \mathrm{H} 8$

$\mathrm{MgH} 0.53$
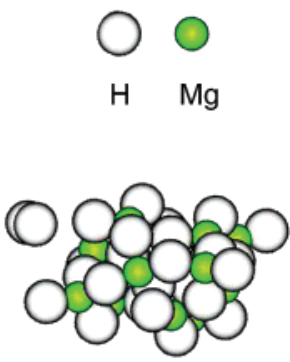

$\mathrm{Mg} 15 \mathrm{H}_{32}$

$\mathrm{MgH}_{2.13}$
Figure 6. A few selected geometries of $\mathrm{Mg}_{6} \mathrm{H}_{x}$ and $\mathrm{Mg}_{15} \mathrm{H}_{x}$ clusters.

Reaction 3 illustrates the process and the clusters involved.

$$
\begin{aligned}
\mathrm{Mg}_{x} \mathrm{H}_{2 x} \rightarrow \mathrm{Mg}_{x} \mathrm{H}_{2 x-2}+\mathrm{H}_{2} & \rightarrow \rightarrow \rightarrow \\
\mathrm{Mg}_{x} \mathrm{H}_{2}+(x-1) \mathrm{H}_{2} & \rightarrow \mathrm{Mg}_{x}+\mathrm{xH}_{2}
\end{aligned}
$$

For each extracted hydrogen molecule the energies of the products were calculated with the DFT (B97) method, resulting in the relative desorption energies shown in Figure 5. Figure 6 shows the corresponding geometries. Additionally, data for a $\mathrm{Mg}_{9} \mathrm{H}_{x}$ cluster are given in the Supporting Information. For the $\mathrm{Mg}_{15} \mathrm{H}_{x}$ cluster, the desorption energy is constant over a broad range. From $\mathrm{MgH}_{2}$ down to $\mathrm{MgH}_{0.4}$ (100-20\% loading) the energy needed to extract one $\mathrm{H}_{2}$ molecule remains around a mean value of $77 \mathrm{~kJ} \cdot \mathrm{mol}\left[\mathrm{H}_{2}\right]^{-1}$. This value is close to experimental data for bulk $\mathrm{MgH}_{2} .{ }^{9}, 13,61,62$ The sudden transition close to $\mathrm{MgH}_{0.5}$ might suggest a more stable sub-hydride phase. However, a closer examination of the geometries (Figure 6, $\mathrm{Mg}_{15} \mathrm{H}_{8}$ ) does not support the existence of such a well-defined phase.

Going from $20 \%$ hydrogen loading downward, the calculated partial desorption enthalpy more than doubles: 174 for $\mathrm{MgH}_{0.13}$

(61) Stampfer, J. F.; Holley, C. E.; Suttle, J. F. J. Am. Chem. Soc. 1960, 82, 3504 .
$\left(\mathrm{Mg}_{15} \mathrm{H}_{2}\right)$ versus $77 \mathrm{~kJ} \cdot \mathrm{mol}\left[\mathrm{H}_{2}\right]^{-1}$ for $\mathrm{MgH}_{0.4-2.0}\left(\mathrm{Mg}_{15} \mathrm{H}_{6-30}\right)$. This indicates that the last few hydrogen molecules are more difficult to release, in this case especially the last two hydrogen molecules, which account for $13 \%$ of the hydrogen content. If we take this relatively large cluster as representative for the bulk system, this result gives a possible explanation why the theoretical $7.7 \mathrm{wt} \%$ reversible hydrogen uptake is usually not achieved in hydrogen absorption/desorption cycles for bulk $\beta-\mathrm{MgH}_{2}$ when the applied desorption temperatures and pressures are close to the equilibrium values. Looking at the geometries in Figure 6, it is remarkable that the last two hydrogen atoms in the $\mathrm{Mg}_{15}$ cluster are not located in the center of the particle. In general, the hydrogen atoms tend to cluster together instead of being evenly distributed.

Hydrogen-enriched clusters were also taken into account. Two or four extra hydrogen atoms were added to the $\mathrm{Mg}_{15} \mathrm{H}_{30}$ cluster, leading to a potential hydrogen loading of $\mathrm{MgH}_{2.13}(107 \%)$ and $\mathrm{MgH}_{2.27}$ (113\%). During the geometric optimizations these extra hydrogen atoms did not dramatically distort the $\mathrm{Mg}_{15} \mathrm{H}_{30}$ structure to occupy an intermetallic position, but remained on the surface. This indicates that these extra hydrogen atoms are not absorbed into, but rather adsorbed onto, the cluster, as is confirmed by the geometries of $\mathrm{Mg}_{15} \mathrm{H}_{32}$ and $\mathrm{Mg}_{6} \mathrm{H}_{14}$ in Figure 6. In both cases the "excess" hydrogens are not dissociated, and are bound to the surface as a hydrogen molecule at a relatively large distance from a $\mathrm{Mg}$ surface atom. The possibility of this adsorption depends on the specific surface area, and is therefore less pronounced in bulk systems. Figure 5 shows that these small $\mathrm{MgH}_{2}$ particles have the potential to take up 10$15 \%$ extra hydrogen. These extra hydrogen atoms are less strongly bound to the hydride structure and can therefore be released at lower temperatures.

For the $\mathrm{Mg}_{6} \mathrm{H}_{x}$ cluster the energy trend in the stepwise desorption is distinctly different, indicating a nonbulk behavior. With a decreasing amount of hydrogen in the cluster, the desorption energy decreases. This indicates that, upon desorbing hydrogen, the $\mathrm{Mg}_{6} \mathrm{H}_{x}$ cluster becomes less stable and a lower desorption temperature is needed. Also, in this case, excess hydrogen atoms can be bound to the surface as a hydrogen molecule.

3.5. Implications for Hydrogen Storage. The calculated reduction in desorption energy for clusters with fewer than 19 $\mathrm{Mg}$ atoms indicates a lower equilibrium desorption temperature for $\mathrm{MgH}_{2}$. This beneficial change in physical properties might enable the use of magnesium for hydrogen storage. The requirement of such small clusters $\left(\mathrm{Mg}_{9} \mathrm{H}_{18}\right.$ corresponds to a cluster size of $0.9 \mathrm{~nm}$ and a desorption temperature of $473 \mathrm{~K}$ ) does not imply that the particles of magnesium need to be that small. Since only the crystallite size should be small, small grains could make up a larger aggregate, similar to what is observed at an order of magnitude larger scale with particles obtained with ball milling or sputtering of magnesium compounds. ${ }^{18,27,28}$

Lower desorption temperatures are also reported for a special phase of magnesium hydride, $\gamma-\mathrm{MgH}_{2}$, which can be obtained by reactive ball milling of $\beta-\mathrm{MgH}_{2} \cdot{ }^{9,13,29-33}$ For bulk systems the $\gamma-\mathrm{MgH}_{2}$ is less stable than the $\beta$-form, which results in a lower desorption temperature. The calculated geometries for clusters smaller than $\mathrm{Mg}_{13} \mathrm{H}_{26}$ show no obvious similarity to

(62) Zaluski, L. U.S. Patent 6,342,798, 1997. 
either $\beta$ - or $\gamma-\mathrm{MgH}_{2}$. More importantly, because of the relative instability, the $\gamma$-structure is lost upon hydrogen cycling, being converted into $\beta-\mathrm{MgH}_{2}$. In contrast, the geometries we calculated for the small clusters are the most stable geometries; hence no phase transition is expected as long as the small particle size is preserved.

As expected from the Born-Haber cycle, the downsizing of the $\mathrm{MgH}_{2}$ and the $\mathrm{Mg}$ structure leads to a change in the lattice, which results in the change in desorption energy via the changed lattice energies. The corresponding possible lower desorption temperatures for clusters smaller than $\operatorname{Mg}_{19}\left(\mathrm{H}_{38}\right)$ suggest a resemblance to (the structure of) amorphous $\mathrm{Mg}$. It would be very interesting to experimentally verify our theoretical results for small $\mathrm{Mg}\left(\mathrm{H}_{2}\right)$ clusters. We will report on the experimental challenge of the synthesis and stabilization of (sub)nanometersized Mg particles in a future paper. The possibility of making the thermodynamics of sorption more favorable by lowering the desorption energy could have a major impact on the efficiency of magnesium-based hydrogen storage materials. Furthermore, the results of our calculations can most likely be extended to other hydrogen storage materials, including complex hydrides like $\mathrm{Mg}\left(\mathrm{AlH}_{4}\right)_{2}$, and to other areas such as reactions involving nanometer-sized catalytic systems.

\section{Conclusions}

The energies of $\mathrm{Mg}$ and $\mathrm{MgH}_{2}$ clusters of up to $56 \mathrm{Mg}$ atoms were calculated with Hartree-Fock and density functional theory methods. Magnesium hydride clusters larger than $\mathrm{Mg}_{19} \mathrm{H}_{38}$ have a rutile-like geometry, similar to that of bulk $\beta-\mathrm{MgH}_{2}$. The calculated desorption energy for clusters with $56 \mathrm{Mg}$ atoms is roughly in agreement with the experimental bulk desorption enthalpy of $75 \mathrm{~kJ} \cdot \mathrm{mol}\left[\mathrm{H}_{2}\right]^{-1}{ }^{61}$ The calculations show that $\mathrm{MgH}_{2}$ is more destabilized than $\mathrm{Mg}$ upon decreasing the cluster size below $19 \mathrm{Mg}$ atoms. This translates to a decrease in desorption energy and, hence, a significantly lower hydrogen desorption temperature for these small $\mathrm{MgH}_{2}$ clusters. A cluster of $0.9 \mathrm{~nm}$ would correspond to a desorption temperature of 473 K.

A stepwise calculation on the hydrogen sorption processes shows that magnesium has the potential to take up a few additional percent of hydrogen above the stoichiometric $\mathrm{MgH}_{2}$. These extra hydrogen atoms are adsorbed to, rather than absorbed in, the hydride structure. For almost discharged bulklike magnesium hydride clusters, the last $13 \%$ of the hydrogen is more difficult to extract. However, for the destabilized smaller clusters, hydrogen extraction becomes easier.

Our calculations clearly show that small $\mathrm{MgH}_{2}$ clusters have a much lower desorption energy than bulk $\mathrm{MgH}_{2}$, hence enabling hydrogen desorption at lower temperatures. At the moment, high desorption temperatures are a major impediment; hence the projected shift toward more favorable operation temperatures is crucial for the application of $\mathrm{Mg}$ as a reversible hydrogen storage material.

Acknowledgment. We acknowledge partial financial support from NWO/NCF for the use of supercomputer time on TERAS, SARA, The Netherlands, Project No. SG-032.

Supporting Information Available: Desorption energies and cluster geometries. This material is available free of charge via the Internet at http://pubs.acs.org.

JA054569H 